\title{
Urinary albumin excretion and prevalence of microalbuminuria in a general Chinese population: a cross-sectional study
}

Liuxia Yan ${ }^{1}$, Jixiang Ma ${ }^{1}$, Xiaolei Guo ${ }^{2,3}$, Junli Tang ${ }^{2,3}$, Jiyu Zhang ${ }^{2,3}$, Zilong Lu², ${ }^{2,3}$ Huicheng Wang ${ }^{4}$, Xiaoning Cai ${ }^{1}$ and Linhong Wang ${ }^{1 *}$

\begin{abstract}
Background: Microalbuminuria has been shown to be a risk factor for cardiovascular and renal disease in patients with hypertension and diabetes as well as in the general population. Urinary albumin excretion over $24 \mathrm{~h}$ is considered a 'gold standard' to detect microalbuminuria. Few studies have used 24-h urinary albumin excretion to analyze the prevalence of and related factors for microalbuminuira in a general Chinese population.

Methods: This study included 1980 adults aged 18-69 years from the Shandong-Ministry of Health Action on Salt and Hypertension (SMASH) Project 2011 survey. Blood pressure, height, weight and waist circumference were measured, and a venous blood and timed 24-h urine samples were collected from each participant. Linear and logistic regression analyses were used to test associations between established cardiovascular risk factors and microalbuminuria.

Results: The median (25th-75th percentile) of 24-h urinary albumin excretion was $6.1 \mathrm{mg} / \mathrm{d}$ (4.5-8.7 mg/d) for all adults, $6.0 \mathrm{mg} / \mathrm{d}(4.4-8.5 \mathrm{mg} / \mathrm{d})$ for men and $6.2 \mathrm{mg} / \mathrm{d}(4.6-8.9 \mathrm{mg} / \mathrm{d})$ for women. The overall prevalence of microalbuminuria was $4.1 \%$ (95\% confidence interval [Cl]: 3.2-5.0\%), 3.7\% (95\% Cl: 2.9-4.5\%) for men and 4.6\% ( $95 \%$ Cl: $3.7-5.5 \%)$ for women. Microalbuminuria was present in 8.1\% (95\% Cl: 6.9-9.3\%) of individuals with hypertension, $11.4 \%$ (95\% Cl: 10.0-12.8\%) of those with diabetes and 15.6\% (95\% Cl: 14.0-17.2\%) of those with both. Multiple logistic regression analysis indicated that systolic blood pressure (odds ratio [OR] 1.02; 95\% Cl: 1.01-1.03) and fasting blood glucose (OR 1.19; 95\% Cl: 1.05-1.35) were the independent risk factors for microalbuminuria.

Conclusions: Adults in the general population of Shandong Province have a moderate prevalence of microalbuminuria. Those with hypertension and diabetes are at high risk of having microalbuminuria, suggesting the need for screening and early intervention for microalbuminuria among these individuals.
\end{abstract}

Keywords: Diabetes, Hypertension, Microalbuminuria

\section{Background}

Microalbuminuria (MAU), an abnormal increase in the urinary excretion of albumin, is a risk factor for cardiovascular and renal disease in patients with hypertension and diabetes [1-4]. Early intervention for MAU among the patients with hypertension and diabetes has been shown to reduce their risks of progression of renal and

\footnotetext{
* Correspondence: linhong@chinawch.org.cn

${ }^{1}$ National Center for Chronic and Noncommunicable Disease Control and Prevention, Chinese Center for Disease Control and Prevention, Beijing 100050, China

Full list of author information is available at the end of the article
}

cardiovascular complications [5,6]. International guidelines therefore recommend that patients with hypertension and diabetes be screened for MAU, enhancing the benefits of early diagnosis and treatment $[7,8]$.

MAU has also been shown to be predictive of cardiovascular events and all cause mortality in the general population [9-11]. In middle-aged to elderly-aged Chinese adults, the risk of cardiovascular mortality is about threefold higher in individuals with than without MAU [9]. Additionally, MAU was independently associated with other cardiovascular risk factors [12,13]. Screening for 
MAU may result in the earlier detection and treatment of undiagnosed cardiovascular disease [13,14].

The amount of urinary albumin excreted over a $24-\mathrm{h}$ period is considered the 'gold standard' for defining MAU [3]. However, owing to the inconvenience and cumbersomeness of 24-h urine collection, spot urine measurements of albumin concentration or albumin to creatinine ratio are used as alternatives in clinical practice [15-17]. Indeed, the previous studies of MAU in Chinese adults were assessed using the alternative methods, not by measuring 24-h urinary albumin excretion. This study therefore assessed the prevalence of MAU in a general Chinese population by analyzing 24-h urine secretion, as well as analyzing the association between MAU and established risk factors for cardiovascular disease.

\section{Methods}

\section{Subjects}

The study subjects had participated in the ShandongMinistry of Health Action on Salt and Hypertension (SMASH) project 2011 survey; the methods used for this survey have been described in detail [18]. Using a stratified multi-stage cluster sampling method, 2112 adults aged 18-69 years were selected from 20 counties and districts across Shandong Province. All the participants were required to complete a face-to-face questionnaire survey, undergo an anthropometric examination and provide fasting blood and timed 24-h urine samples. This study was conducted according to the guidelines of the Declaration of Helsinki, and all procedures involving human subjects were approved by the Ethics Committee of the Shandong Center for Disease Control and Prevention. Written informed consent was obtained from each subject.

\section{Anthropometric measurements}

Physical examinations, including measurements of height, weight, waist circumference and blood pressure, were performed by trained health professionals. Weight was measured barefoot and in light-clothing. Body mass index (BMI) was calculated as weight in kilograms divided by the square of height in meters. Underweight, normal weight, overweight and obesity were defined as $\mathrm{BMI}<18.5 \mathrm{~kg} / \mathrm{m}^{2}, \geq 18.5$ but $<24 \mathrm{~kg} / \mathrm{m}^{2}, \geq 24$ but $<28 \mathrm{~kg} / \mathrm{m}^{2}$ and $\geq 28 \mathrm{~kg} / \mathrm{m}^{2}$ respectively according to Chinese guidelines [19].

Blood pressure was measured in a sitting position three times every $5 \mathrm{~min}$ on one occasion using an electronic sphygmomanometer (HEM-7071, Omron Corporation, Japan), with the average of the three measures defined as individual blood pressure. Hypertension was defined as systolic blood pressure (SBP) $\geq 140 \mathrm{mmHg}$ or diastolic blood pressure (DBP) $\geq 90 \mathrm{mmHg}$, or self-reported taking of anti-hypertensive medications [20].

\section{Blood sample collection and biochemical assays}

A morning sample of venous blood was drawn from each participant and centrifuged within $2 \mathrm{~h}$ of collection. Participants with fasting blood glucose $\geq 6.1 \mathrm{mmol} / \mathrm{L}$ were invited to return for an oral glucose tolerance test (OGTT) on another day, at which time $2 \mathrm{~h}$ postload blood glucose (2hPBG) was tested.

Serum samples were frozen at $-80^{\circ} \mathrm{C}$. All blood and 24-h urine sample were assessed by ADICON Clinical Laboratory Inc., Jinan, Shandong. Serum glucose, total cholesterol, high-density lipoproteins, low-density lipoproteins and triglycerides were measured by standard laboratory methods on an Olympus AU640.

Diabetes was diagnosed according to the standard of the American Diabetes Association (2003) [21]. Participants were defined as having type 2 diabetes if they had fasting serum glucose $\geq 7.0 \mathrm{mmol} / \mathrm{L}, 2 \mathrm{hPBG} \geq 11.1 \mathrm{mmol} / \mathrm{L}$, or validated history of diabetes as diagnosed by a physician. Dyslipidaemia was defined as elevated serum concentrations of total cholesterol $(\mathrm{TC}) \geq 6.1 \mathrm{mmol} / \mathrm{L}$, and/or triacylglycerol (TG) $\geq 2.26 \mathrm{mmol} / \mathrm{L}$, and/or LDLcholesterol (LDL-C) $\geq 4.14 \mathrm{mmol} / \mathrm{L}$, and/or a decreased HDL-cholesterol (HDL-C) concentration of $<1.0 \mathrm{mmol} / \mathrm{L}$ as described by the American National Cholesterol Education Program (Adult Treatment Panel III) [22].

\section{4-h urine collection and measurements}

Participants were instructed on the methods of collection of a standard 24-hour urine sample. Each participant was given a standard plastic container containing about $1 \mathrm{~g}$ boric acid as a preservative. Participants were instructed to discard the first void and collect all the urine during the following $24 \mathrm{~h}$ in the container. A local health professional recorded the starting and ending times of each collection and determined the exact duration of collection. Each participant was interviewed using a standard questionnaire to assess the completeness of urine collection. Urine volume was measured on a standard platform at each field site by a laboratory technician. The collected urine samples were kept in a freezer at $-20^{\circ} \mathrm{C}$ and were delivered to ADICON Clinical Laboratory Inc for laboratory testing. Individual urinary albumin and creatinine excretion were calculated as the products of their concentrations in the urine and urinary volume, corrected to $24 \mathrm{~h}$.

\section{Evaluation of albuminuria}

Urinary creatinine excretion was assessed using the picric acid method, and 24-h urinary albumin excretion (UAE) was assessed using an immunonephelometric method, both on an Olympus AU640 Analyzer. The albumin to 
creatinine ratio (ACR) was calculated, as were the agreements between albuminuria as determined by UAE and by ACR. For UAE, <30 mg/d, 30-299 mg/d and $\geq 300 \mathrm{mg} / \mathrm{d}$ were defined as normal, microalbuminuria and macroalbuminuria. The corresponding value for ACR was $<30 \mathrm{mg} / \mathrm{g}, 30-299 \mathrm{mg} / \mathrm{g}$ and $\geq 300 \mathrm{mg} / \mathrm{g}$, respectively.

Each 24-h urine sample was assessed for completeness using urinary volume and gender specific urinary creatinine cut-off point. Incompleteness was defined as 24-h urinary volume $<500 \mathrm{ml}$, and/or 24-h urinary creatinine $<1.91$ or $>18.27 \mathrm{mmol}$ in men, or $<1.36$ or $>14.28 \mathrm{mmol}$ in women, with these samples excluded from analysis.

Of the 2112 participants, 88 provided incomplete $24-\mathrm{h}$ urine collection, and 44 failed to provide the blood sample. Thus, the study involved 1980 participants.

\section{Statistical analysis}

Normally distributed and continuous variables were expressed as mean \pm standard deviation (SD), and the differences between gender were assessed by $\mathrm{t}$ test. Mean and percentile values (i.e. P5, P25, P50, P75 and P95) of 24-h UAE were analyzed. The prevalence of microalbuminuria was reported as a percentage with 95\% confidence intervals (CI). Of the 1980 participants, only two were classified as having macroalbuminuria, therefore, only factors associated with the prevalence of microalbuminuria were analyzed with differences between the proportions of subjects with microalbuminuria assessed by Fisher's Exact test or the Chi-square test. Agreement in the classification of albuminuria by measurements of UAE and ACR was summarized by Cohen's k [23].

Two methods were used for multiple regression analysis. First, a stepwise multiple linear regression analysis was performed. Because UAE was not normally distributed, $\log (\mathrm{n}) \mathrm{UAE}$ was considered the dependent variable, with age, gender, smoking (yes/no), BMI, SBP(mmHg), $\mathrm{FBG}(\mathrm{mmol} / \mathrm{l})$ and $\mathrm{TC}(\mathrm{mmol} / \mathrm{l})$ considered independent variables. The regression model also analyzed HDL-C, LDL-C and TG concentrations as covariates. Second, multiple stepwise logistic regression analysis was performed to assess factors associated with microalbuminuria. The dependent variable was microalbuminuria (yes/no), with the covariates the same as those described above.

Statistical analyses were performed with SAS 9.3 (SAS Institute Inc., Cary, North Carolina, USA). A P value $<0.05$ was considered statistically significant.

\section{Results}

Clinical characteristics of the study population

Out of the 1980 participants, 52.4\% were male, and their average age was 41 years old ( $\mathrm{SD}=14.0$ years).
Approximately $25 \%$ of the participants were hypertensive, with a median (Q1-Q3) hypertension duration of 3.0 (1.3-7.5) years. About 6.2\% had diabetes, and $23.6 \%$ had dyslipidaemia. The average BMI was $24.5 \mathrm{~kg} / \mathrm{m}^{2}$ and $17.8 \%$ of the participants were obese (Table 1 ).

\section{Distribution of 24-h UAE}

The overall median (P25-P75) 24-h UAE was 6.1 (4.58.7) $\mathrm{mg} / \mathrm{d}, 6.0$ (4.4-8.5) $\mathrm{mg} / \mathrm{d}$ for men and 6.2 (4.6-8.9) $\mathrm{mg} / \mathrm{d}$ for women. The median (P25-P75) 24-h UAEs among subjects with hypertension and diabetes were 6.7 $(4.8-10.8) \mathrm{mg} / \mathrm{d}$ and $7.6(5.3-11.3) \mathrm{mg} / \mathrm{d}$ respectively (Table 2).

\section{Prevalence of microalbuminuria}

The prevalence of MAU among general Shandong adults was $4.1 \%$ (95\% CI: $3.2-5.0 \%), 3.7 \%$ (95\% CI: $2.9-4.5 \%)$ for men and $4.6 \%$ (95\% CI: 3.7-5.5\%) for women. MAU was present in $8.1 \%$ (95\% CI: $6.9-9.3 \%$ ) of the participants with hypertension, and in $11.4 \%$ (95\% CI: $10.0-$ $12.8 \%$ ) of those with diabetes, with the prevalence in each of these subgroups significantly higher than in subgroups

Table 1 Characteristics of the study population by gender

\begin{tabular}{|c|c|c|c|c|}
\hline & $\begin{array}{l}\text { Men } \\
\text { (n 1038) }\end{array}$ & $\begin{array}{l}\text { Women } \\
\text { (n 942) }\end{array}$ & $\begin{array}{l}\text { Total } \\
\text { (n 1980) }\end{array}$ & $\mathbf{P}$ \\
\hline Age (years) & $41.4 \pm 14.2$ & $41.4 \pm 13.6$ & $41.4 \pm 14.0$ & 0.76 \\
\hline Current smoking,\% & 47.4 & 2.7 & 26.1 & $<0.001$ \\
\hline BMI $\left(\mathrm{kg} / \mathrm{m}^{2}\right)$ & $24.5 \pm 3.9$ & $24.5 \pm 3.9$ & $24.5 \pm 3.9$ & 0.94 \\
\hline Waist circumference (cm) & $85.5 \pm 11.4$ & $81.6 \pm 10.8$ & $83.7 \pm 11.3$ & $<0.001$ \\
\hline \multicolumn{5}{|l|}{ Blood pressure } \\
\hline $\mathrm{SBP}(\mathrm{mmHg})$ & $124.7 \pm 17.9$ & $118 \pm 19.2$ & $121.5 \pm 18.8$ & $<0.0001$ \\
\hline $\mathrm{DBP}(\mathrm{mmHg})$ & $80.5 \pm 11.5$ & $77.1 \pm 11.2$ & $78.9 \pm 11.5$ & $<0.0001$ \\
\hline Serum FBG (mmol) & $5.5 \pm 1.2$ & $5.5 \pm 1.1$ & $5.5 \pm 1.1$ & 0.50 \\
\hline Dyslipidemia,\% & 28.0 & 18.8 & 23.6 & $<0.0001$ \\
\hline $\mathrm{TC}(\mathrm{mmol})$ & $4.4 \pm 0.9$ & $4.4 \pm 1.0$ & $4.4 \pm 0.9$ & 0.74 \\
\hline High TC,\% & 3.8 & 4.1 & 3.9 & 0.60 \\
\hline HDLC (mmol) & $1.4 \pm 0.4$ & $1.5 \pm 0.3$ & $1.4 \pm 0.3$ & 0.10 \\
\hline Low HDL,\% & 14.6 & 8.3 & 11.3 & $<0.0001$ \\
\hline LDLC (mmol) & $2.2 \pm 0.6$ & $2.2 \pm 0.6$ & $2.2 \pm 0.6$ & 0.30 \\
\hline High LDL,\% & 0.6 & 1.0 & 0.8 & 0.33 \\
\hline TG (mmol) & $1.6 \pm 1.9$ & $1.2 \pm 1.1$ & $1.4 \pm 1.6$ & $<0.001$ \\
\hline High TG,\% & 15.8 & 10.7 & 13.4 & 0.0008 \\
\hline Hypertension,\% & 25.0 & 22.2 & 23.7 & 0.15 \\
\hline Diabetes, $\%$ & 5.8 & 6.7 & 6.2 & 0.40 \\
\hline Obese, $\%$ & 17.6 & 18.0 & 17.8 & 0.81 \\
\hline \multicolumn{5}{|l|}{ Urinary excretion } \\
\hline Volume (ml/d) & $1582 \pm 660$ & $1501 \pm 587$ & $1544 \pm 627$ & 0.004 \\
\hline Creatinine $(\mathrm{mmol} / \mathrm{d})$ & $9.8 \pm 3.3$ & $7.5 \pm 2.2$ & $8.7 \pm 3.1$ & $<0.001$ \\
\hline
\end{tabular}


Table 2 24-h urinary albumin excretion $(\mathrm{mg} / \mathrm{d})$ and prevalence of microalbuminuria (\%, $95 \% \mathrm{Cl})$ by selected risk factors

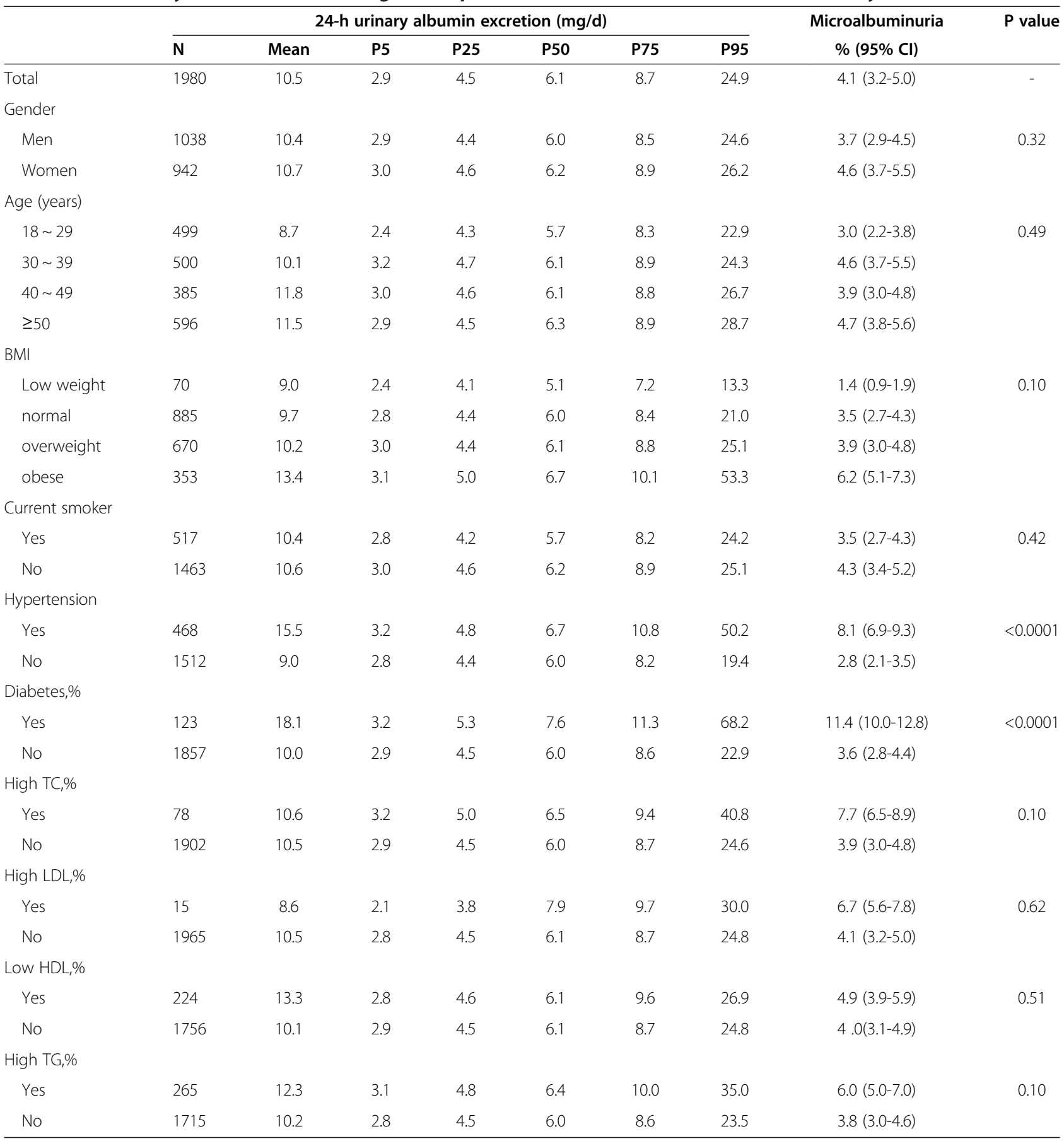

without hypertension or diabetes, respectively $(\mathrm{P}<0.0001)$ (Table 2). The prevalence of MAU in participants with both hypertension and diabetes was 15.6\% (95\% CI: $14.0-17.2 \%)$.

The prevalence of MAU increased with the duration of hypertension $\left(\mathrm{P}_{\text {trend }}=0.03\right)$. Relative to median disease duration (3 years), the prevalence of MAU was $8.7 \%$ (95\% CI:7.5-9.9\%) in subjects with hypertension $<3$ years and $12.5 \%$ (95\% CI:11.0-14.0\%) in subjects with hypertension $>3$ years (Figure 1).

Among the participants not receiving anti-hypertensive treatment, there were linear trend relationships between the prevalence of MAU and SBP $\left(\mathrm{P}_{\text {trend }}=0.003\right)$ and DBP $\left(\mathrm{P}_{\text {trend }}<0.0001\right)$ levels (Figure 2$)$.

The prevalence of MAU increased with numbers of cardiovascular risk factors $\left(\mathrm{P}_{\text {trend }}<0.001\right)$. Its prevalence 


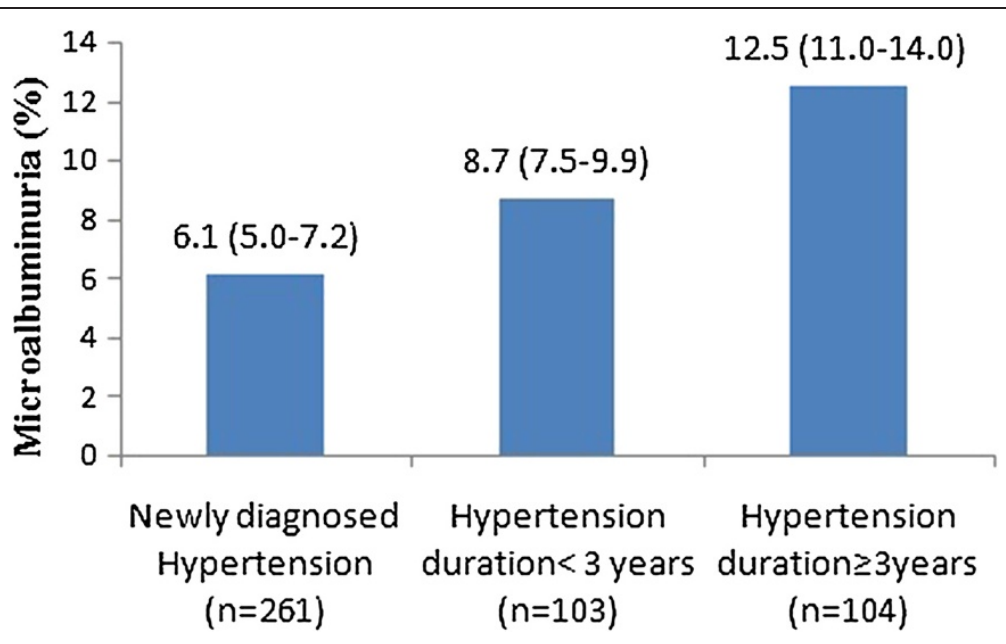

Figure 1 Unadjusted prevalence of microalbuminuria $(\%, 95 \% \mathrm{Cl})$ by duration of hypertension.
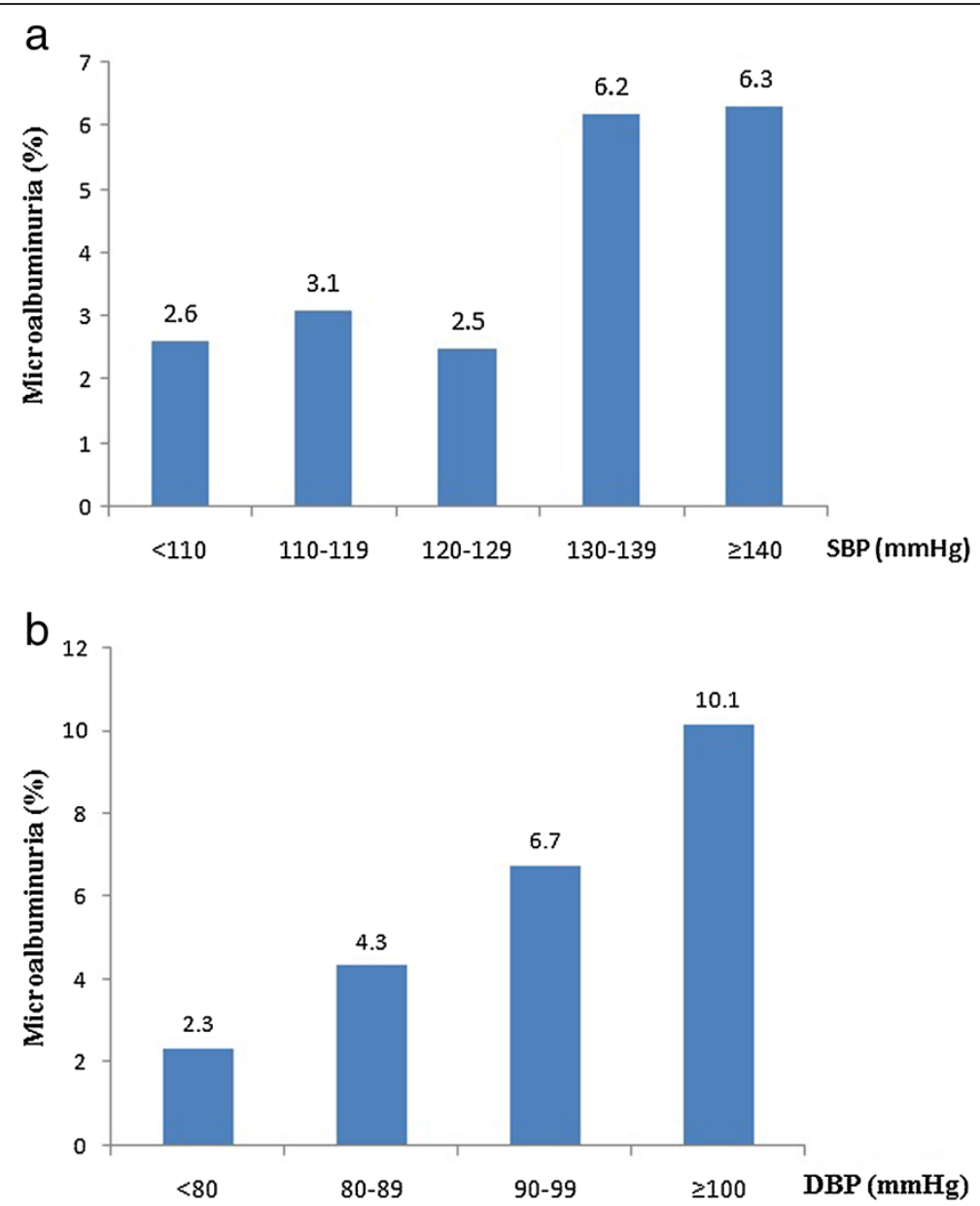

Figure 2 Unadjusted prevalence of microalbuminuria (\%) by SBP and DBP levels in the participants not treated with anti-hypertensive drugs. a. Unadjusted prevalence of microalbuminuria by SBP level (<110 mmHg, $110-119 \mathrm{mmHg}, 120-129 \mathrm{mmHg}, 130-139 \mathrm{mmHg}, \geq 140 \mathrm{mmHg})$ in participants not treated with anti-hypertensive drugs. The rates of MAU (\%, 95\% Cl) in these groups were 2.6\% (95\% Cl: 1.9-3.3\%), 3.1\% (95\% Cl: 2.3-3.9\%), 2.5\% (95\% Cl: 1.8-3.2\%), 6.2\% (95\% Cl: 5.1-7.3\%), 6.3\% (95\% Cl: 5.2-7.4\%). b. Unadjusted prevalence of microalbuminuria by DBP level (DBP $<80 \mathrm{mmHg}, 80-89 \mathrm{mmHg}, 90-99 \mathrm{mmHg}, \geq 100 \mathrm{mmHg}$ ) in the participants not treated with anti-hypertensive drugs. The rates (\%, 95\% Cl) of MAU in these groups were 2.3\% (95\% Cl: 1.6-3.0\%), 4.3\% (95\% Cl: 3.4-5.2\%), 6.7\% (95\% Cl: 5.6-7.8\%), 10.1\% (95\% Cl: 8.8-11.4\%). 
among the participants without hypertension, diabetes, obesity or dyslipdaemia was $2.6 \%$ (95\% CI: $1.9-3.3 \%$ ), whereas its prevalence in the participants with $>3$ risk factors was $9.8 \%$ (95\% CI: 8.5-11.1\%) (Figure 3).

\section{Agreement between albuminuria assessed by measuring of UAE and ACR}

Table 3 shows the agreement between the prevalence of albuminuria as determined by measuring of UAE and ACR. The overall k index was 0.86 (95\% CI: 0.80-0.91).

\section{Risk factors for 24-h UAE and microalbuminuria}

Linear regression analysis indicated that smoking, BMI, SBP and LDL-C were independently associated with the $\log (\mathrm{n}) \mathrm{UAE}$. BMI and SBP were positively associated with UAE, while smoking and LDL-C were negatively associated (Table 4).

Multiple logistic regression analysis showed that SBP and FBG were independent risk factors for the development of MAU, FBG was the most important risk factor for MAU progression, with an odds ratio [OR] of 1.19 (95\% CI: 1.05-1.35) (Table 5).

\section{Discussion}

Albuminuira, a component of the increasing disease burden of chronic kidney disease in China, has been a public health concern. This survey of communitydwelling Chinese adults aged 18 to 69 years and living in Shandong Province found that $4.1 \%$ had MAU, as defined by 24-h UAE, with MAU being more prevalent in the subjects with hypertension (8.1\%) and diabetes (11.4\%). Disease duration, blood pressure and serum glucose level were associated with MAU; therefore, both blood pressure and glucose should be controlled as much as possible to prevent the progression of MAU.
The prevalence of MAU in Shandong adults was lower in other regions in China (4.5-15\%) [12,24-26]. This discrepancy may be associated with geographic regional differences or the characteristics of the sampled population (e.g. age and cardiovascular disease profiles). In addition, MAU was defined in our study by 24-h UAE, whereas in other studies, MAU was defined by ACR or UAC. These measurements were moderately correlated and were comparable in predicting for cardiovascular disease mortality in prospective studies [17]. We observed substantial agreement of MAU classifications by measuring UAE and ACR in the same timed 24-h urine samples. However, there were still systematic differences in the classification of albuminuria prevalence [27]. Validation studies are required to determine the correlation between MAU as determined by 24-h UAE, as determined by ACR or UAC from untimed spot urine samples in Chinese population.

In agreement with previous studies, we found that hypertensive individuals were at high risk for MAU, with blood pressure linearly associated with MAU [12,24,28,29]. A recent national hypertension survey in China found that blood pressure was controlled under 140/90 $\mathrm{mmHg}$ in 9.3\% of hypertensive individuals [30]. In comparison, we found that blood pressure was controlled in 14.9\% hypertensive adults in Shandong Province [18]. Uncontrolled blood pressure may increase the risk of MAU progression. Recent hypertension management guideline have recommended that patients of any age with MAU initiate pharmacologic treatment to lower blood pressure [8]. Therefore, more aggressive preventive and/or treatment strategies are needed to control blood pressure in hypertensive patients with MAU.

MAU is the first sign of diabetic nephropathy. The percentage of our diabetic patients with MAU was much lower than the previously reported prevalence in China

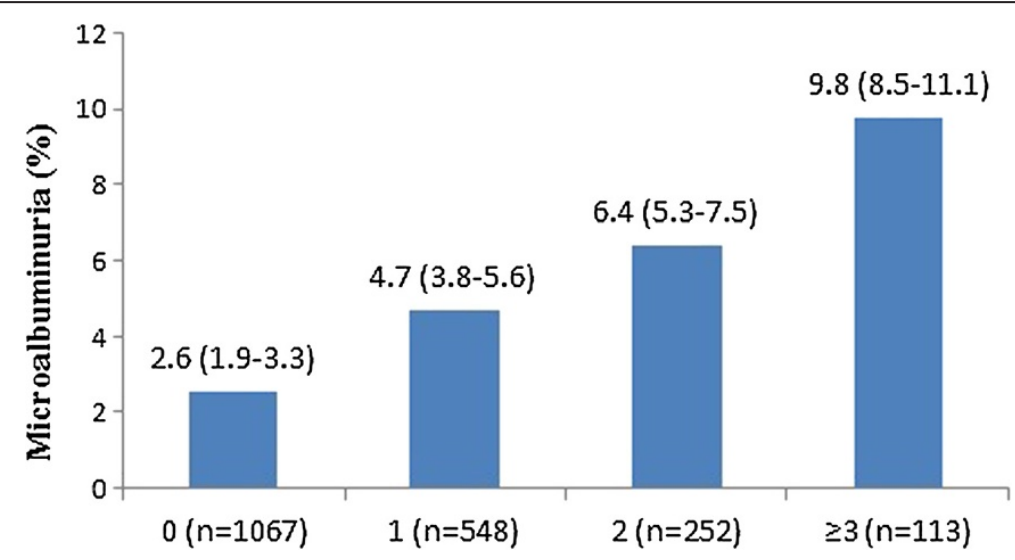

Figure 3 Unadjusted prevalence of microalbuminuria $(\%, 95 \% \mathrm{Cl})$ by number of cardiovascular disease risk factors, including hypertension, diabetes, dyslipidaemia and obesity. 
Table 3 Agreement of albuminuria defined by $24 \mathrm{~h}$ urinary albumin excretion and $24 \mathrm{~h}$ albumin to creatinine ratio

\begin{tabular}{|c|c|c|c|c|c|c|c|c|}
\hline \multicolumn{2}{|c|}{ Albumin to creatinine ratio (ACR) } & \multicolumn{6}{|c|}{ Urinary albumin excretion (UAE) } & \multirow[t]{3}{*}{$(95 \% \mathrm{Cl})$} \\
\hline & & \multicolumn{2}{|c|}{$\begin{array}{c}\text { Normal } \\
(<30 \mathrm{mg} / 24 \mathrm{~h})\end{array}$} & \multicolumn{2}{|c|}{$\begin{array}{l}\text { Microalbuminuria } \\
(30-299 \mathrm{mg} / 24 \mathrm{~h})\end{array}$} & \multicolumn{2}{|c|}{$\begin{array}{c}\text { Macroalbuminuria } \\
(\geq 300 \mathrm{mg} / 24 \mathrm{~h})\end{array}$} & \\
\hline & & No. & $\%$ & No. & $\%$ & No. & $\%$ & \\
\hline Normal & $<30 \mathrm{mg} / \mathrm{g}$ & 1882 & 99.2 & 7 & 8.6 & 0 & 0 & $0.86(0.80-0.91)$ \\
\hline Microalbuminuria & $30-299 \mathrm{mg} / \mathrm{g}$ & 15 & 0.8 & 72 & 88.9 & 0 & 0 & \\
\hline Macroalbuminuria & $\geq 300 \mathrm{mg} / \mathrm{g}$ & 0 & 0 & 2 & 2.5 & 2 & 100.0 & \\
\hline
\end{tabular}

and other countries [31-33]. The prevalence of MAU was associated with disease duration [34]. Previous studies, however, usually included hospital-based patients or those with diabetes, with most of these subjects being patients with a history of diabetes. In contrast, most (70\%) of the diabetic patients participated in our study were initially diagnosed in this survey. Furthermore, those previously diagnosed had a relative short disease duration (average 2.4 years).

We also found that MAU was associated with obesity and dyslipidemia [35,36], with the prevalence of MAU strongly related to the number of established cardiovascular disease risk factors. The Metabolic Syndrome-a cluster of the risk factors including elevated blood pressure, fasting blood glucose, BMI and serum cholesterol-was shown to be a predictor of MAU progression, and eventually of overt proteinuira and chronic kidney disease [37,38].

The utility of albuminuira screening in the general population is unclear $[12,14,39-42]$. Despite its predictive value for end-stage kidney disease, cardiovascular disease and death, several factors influence the potential implementation of MAU screening in clinical practice, including the prevalence of MAU in the target population, the type of test performed, the threshold for albuminuria and the cost of screening [39-42]. Results from the Third National Health and Nutrition Examination Survey finding in the United States estimated that screening of 11 (95\% CI: 10-12) adults was required to identify one individual with MAU [14]. Our finding in adults from the Shandong Province suggested that 24 (95\% CI: 20-30) adults would have to be screened to identify one with

Table 4 Linear regression analysis of $24 \mathrm{~h}$ urinary albumin excretion with related covariates*

\begin{tabular}{lcc}
\hline Covariates & $\boldsymbol{\beta}$ & P value \\
\hline Smoking (yes/no) & -0.0008 & 0.02 \\
$\mathrm{BMI}\left(\mathrm{kg} / \mathrm{m}^{2}\right)$ & 0.0165 & 0.0001 \\
$\mathrm{SBP}(\mathrm{mmHg})$ & 0.0043 & $<0.0001$ \\
$\mathrm{LDL}-\mathrm{C}(\mathrm{mmol} / \mathrm{l})$ & -0.0814 & 0.002 \\
\hline
\end{tabular}

*: $\log (\mathrm{n})$ UAE was used as the dependent variable in the linear regression model, with the stepwise method used for selection of variables. The selected variables included age, gender, smoking (yes/no), BMl, SBP $(\mathrm{mmHg})$, FBG $(\mathrm{mmol} / \mathrm{l})$, $\mathrm{TC}(\mathrm{mmol} / \mathrm{l})$, HDL-C (mmol/l), LDL-C (mmol/l) and TG (mmol/l).
MAU. Studies are needed to determine the value of screening for MAU in the general Chinese population.

A major strength of our study was our use of the gold standard 24-h UAE to classify individuals with microalbuminuria, unlike previous studies in Chinese populations. Furthermore, this study included a representative sample of the general population, using rigorously standardized methods for data collection and strict quality control. However, our study has several limitations. First, we collected only one 24-h urine sample per participant, thus preventing a determination of day-to-day variability for each individual [43]. Second, the completeness of 24-h urine collection was assessed by measuring urinary volume and creatinine concentration. Without an objective measure such as $\mathrm{p}$-aminobenzoic acid (PABA), it is difficult to assess the completeness of urine collection [44]. Third, serum creatinine was not measured in our study, therefore, we were unable to determine glomerular filtration rate or the prevalence of chronic kidney disease. Fourth, our study population included only adult residents of Shandong Province, thus limiting the applicability of our results to other populations. Finally, owing to the cross-sectional nature of this study, we were unable to quantify the associations betweenhypertension and diabetes and the progression of MAU. Follow-up studies are therefore recommended.

\section{Conclusions}

This study showed that the prevalence of MAU in the general adult population of Shandong Province, China, is moderate. Rates of MAU were higher in subjects with than without hypertension and diabetes, with these two factors together associated with MAU. Screening of subjects with hypertension and/or diabetes for MAU may result in earlier diagnosis and treatment.

Table 5 Multiple logistic regression analysis of microalbuminuria with related covariates*

\begin{tabular}{lll}
\hline Covariates & OR $(\mathbf{9 5 \%} \mathbf{~ C l})$ & P value \\
\hline SBP $(\mathrm{mmHg})$ & $1.02(1.01-1.03)$ & $<0.001$ \\
FBG $(\mathrm{mmol} / \mathrm{L})$ & $1.19(1.05-1.35)$ & 0.006 \\
\hline
\end{tabular}

*: Stepwise method was used for the variable selection. The selected variables included age, gender, smoking (yes/no), BMI, SBP $(\mathrm{mmHg}), \mathrm{FBG}(\mathrm{mmol} / \mathrm{l})$, TC $(\mathrm{mmol} / \mathrm{l})$, HDL-C $(\mathrm{mmol} / \mathrm{l}), \mathrm{LDL}-\mathrm{C}(\mathrm{mmol} / \mathrm{l})$ and TG $(\mathrm{mmol} / \mathrm{l})$. 


\section{Abbreviations}

MAU: Microalbuminuria; UAE: Urinary albumin excretion; ACR: Albumin to creatinine ratio; UAC: Urinary albumin concentration; BMI: Body mass index; SBP: Systolic blood pressure; DBP: Diastolic blood pressure; FBG: Fasting blood glucose; OGTT: Oral glucose tolerance test; 2hPBG: 2-h postload blood glucose; TC: Total cholesterol; HDL-C: High-density lipoproteins cholesterol; LDL-C: Low-density lipoproteins cholesterol; TG: Triglycerides; SD: Standard deviation; Q: Quartile; P: Percentile; Cl: Confidence interval; OR: Odds ratio.

\section{Competing interests}

The authors declare that they have no competing interests.

\section{Authors' contributions}

LW, JM and XG conceived and designed the study. JT, JZ, ZL, XC and HW collected field data and responsible for quality control. LY and JM analyzed and interpreted the data analyses and drafted the manuscript. All authors read and approved the final manuscript.

\section{Acknowledgements}

The survey was funded by the Chinese Center for Disease Control and Prevention, the National Center for Non-Communicable and Chronic Disease Control and Prevention and the Technical Development Plan in Shandong (implemented by Shandong CDC, 2012GSF11828). The authors thank all the survey investigators from the national, Shandong provincial and county level CDCs and all participants in the survey.

\section{Author details}

${ }^{1}$ National Center for Chronic and Noncommunicable Disease Control and Prevention, Chinese Center for Disease Control and Prevention, Beijing 100050, China. ${ }^{2}$ Academy of Preventive Medicine, Shandong University, Jinan 250014, China. ${ }^{3}$ Shandong Center for Disease Control and Prevention, Jinan 250014, China. ${ }^{4}$ Chinese Center for Disease Control and Prevention, Beijing 102206, China.

Received: 30 June 2014 Accepted: 8 October 2014

Published: 13 October 2014

\section{References}

1. Gerstein HC, Mann JF, Yi Q, Zinman B, Dinneen SF, Hoogwerf B, Hallé JP, Young J, Rashkow A, Joyce C, Nawaz S, Yusuf S, HOPE Study Investigators: Albuminuria and risk of cardiovascular events, death, and heart failure in diabetic and nondiabetic individuals. JAMA 2001, 286(4):421-426.

2. Stehouwer CD, Gall MA, Twisk JW, Knudsen E, Emeis JJ, Parving HH: Increased urinary albumin excretion, endothelial dysfunction, and chronic low-grade inflammation in type 2 diabetes: progressive, interrelated, and independently associated with risk of death. Diabetes 2002, 51(4):1157-1165.

3. Thoenes M, Bramlage P, Khan BV, Schieffer B, Kirch W, Weir MR: Albuminuria: pathophysiology, epidemiology and clinical relevance of an emerging marker for cardiovascular disease. Future Cardiol 2007, 3(5):519-524.

4. Weir MR: Microalbuminuria and cardiovascular disease. Clin J Am Soc Nephrol 2007, 2(3):581-590

5. Mogensen CE: Twelve shifting paradigms in diabetic renal disease and hypertension. Diabetes Res Clin Pract 2008, 82(Suppl 1):S2-S9.

6. Ruilope L, Izzo J, Haller H, Waeber B, Oparil S, Weber M, Bakris G, Sowers J: Prevention of microalbuminuria in patients with type 2 diabetes: what do we know? J Clin Hypertens (Greenwich) 2010, 12(6):422-430.

7. American Diabetes Association: Standards of medical care in diabetes2014. Diabetes Care 2014, 37(Suppl 1):S14-S80

8. James PA, Oparil S, Carter BL, Cushman WC, Dennison-Himmelfarb C, Handler J, Lackland DT, LeFevre ML, MacKenzie TD, Ogedegbe O, Smith SC Jr, Svetkey LP, Taler SJ, Townsend RR, Wright JT Jr, Narva AS15, Ortiz E: 2014 evidence-based guideline for the management of high blood pressure in adults: report from the panel members appointed to the Eighth Joint National Committee (JNC 8). JAMA 2014, 311(5):507-520.

9. Chen YY, Li YY, Lu YH, Dou JT, Wang SY, Lu JM: Albuminuria independently predicts cardiovascular and all-cause mortality in a middle-aged and elderly Chinese population. Scand J Clin Lab Invest 2012, 72(4):281-286.
10. Matsushita K, van der Velde M, Astor BC, Woodward M, Levey AS, de Jong PE, Coresh J, Gansevoort RT, Chronic Kidney Disease Prognosis Consortium: Association of estimated glomerular filtration rate and albuminuria with all-cause and cardiovascular mortality in general population cohorts: a collaborative meta-analysis. Lancet 2010, 375(9731):2073-2081.

11. Yuyun MF, Khaw KT, Luben R, Welch A, Bingham S, Day NE, Wareham NJ, European Prospective Investigation into Cancer in Norfolk (EPIC-Norfolk) population study: Microalbuminuria independently predicts all-cause and cardiovascular mortality in a British population: The European Prospective Investigation into Cancer in Norfolk (EPIC-Norfolk) population study. Int J Epidemiol 2004, 33(1):189-198.

12. Chen $B$, Yang D, Chen $Y, X u W, Y e B, N i$ : The prevalence of microalbuminuria and its relationships with the components of metabolic syndrome in the general population of China. Clin Chim Acta 2010, 411(9-10):705-709.

13. Özyilmaz A, Bakker SJ, de Zeeuw D, de Jong PE, Gansevoort RT, PREVEND Study Group: Selection on albuminuria enhances the efficacy of screening for cardiovascular risk factors. Nephrol Dial Transplant 2010, 25(11):3560-3568.

14. Garg AX, Kiberd BA, Clark WF, Haynes RB, Clase CM: Albuminuria and renal insufficiency prevalence guides population screening: results from the NHANES III. Kidney Int 2002, 61(6):2165-2175.

15. KDIGO: KDIGO 2012 clinical practice guideline for the evaluation and management of chronic kidney disease kidney. 2012, http://www.kdigo. org/clinical_practice_guidelines/pdf/CKD/KDIGO_2012_CKD_GL.pdf.

16. Dyer AR, Greenland P, Elliott P, Daviglus ML, Claeys G, Kesteloot H, Ueshima H, Stamler J, INTERMAP Research Group: Evaluation of measures of urinary albumin excretion in epidemiologic studies. Am J Epidemiol 2004, 160(11):1122-1131.

17. Lambers Heerspink HJ, Brantsma AH, de Zeeuw D, Bakker SJ, de Jong PE, Gansevoort RT, PREVEND Study Group: Albuminuria assessed from first-morning-void urine samples versus 24-hour urine collections as a predictor of cardiovascular morbidity and mortality. Am J Epidemiol 2008 168(8):897-905

18. Bi Z, Liang X, Xu A, Wang L, Shi X, Zhao W, Ma J, Guo X, Zhang X, Zhang J, Ren J, Yan L, Lu Z, Wang H, Tang J, Cai X, Dong J, Zhang J, Chu J, Engelgau M, Yang Q, Hong Y, Wang Y: Hypertension Prevalence, Awareness, Treatment, and Control and Sodium Intake in Shandong Province, China: Baseline Results From Shandong-Ministry of Health Action on Salt and Hypertension (SMASH), 2011. Prev Chronic Dis 2014, 22(11):E88.

19. Bureau of Disease Control and Prevention, China's Ministry of Health: Chinese guideline on adult overweight and obesity prevention. Beijing: People's Medical Publishing House; 2006.

20. The seventh report of the joint national committee on prevention. Detection, evaluation, and treatment of high blood pressure. http://www. nhlbi.nih.gov/files/docs/guidelines/jnc7full.pdf.

21. Expert Committee on the Diagnosis and Classification of Diabetes Mellitus: Report of the expert committee on the diagnosis and classification of diabetes mellitus. Diabetes Care 2003, 26(Suppl 1):S5-S20.

22. Expert Panel on Detection, Evaluation, and Treatment of High Blood Cholesterol in Adults: Executive Summary of the third Report of the National Cholesterol Education Program (NCEP) Expert Panel on Detection, Evaluation, And Treatment of High Blood Cholesterol In Adults (Adult Treatment Panel III). JAMA 2001, 285(19):2486-2497.

23. Cohen J: A coefficient of agreement for nominal scales. Educ Psychol Meas 1960, 20:37-46.

24. Shan Y, Zhang Q, Liu Z, Hu X, Liu D: Prevalence and risk factors associated with chronic kidney disease in adults over 40 years: a population study from Central China. Nephrology (Carlton) 2010, 15(3):354-361.

25. Hao G, Wang Z, Zhang L, Chen Z, Wang X, Guo M, Tian Y, Shao L, Zhu M: Prevalence of microalbuminuria among middle-aged population of china: a multiple center cardiovascular epidemiological study. Angiology 2013

26. Chen W, Chen W, Wang H, Dong X, Liu Q, Mao H, Tan J, Lin J, Zhou F, Luo N, He H, Johnson RJ, Zhou SF, Yu X: Prevalence and risk factors associated with chronic kidney disease in an adult population from southern China. Nephrol Dial Transplant 2009, 24(4):1205-1212.

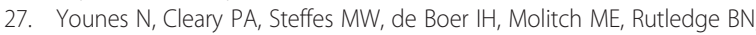
Lachin JM, Dahms W, DCCT/EDIC Research Group: Comparison of urinary albumin-creatinine ratio and albumin excretion rate in the diabetes control and complications trial/epidemiology of diabetes interventions and complications study. Clin J Am Soc Nephrol 2010, 5(7):1235-1242. 
28. Stergiou GS, Alamara C, Drakatos A, Stefanidis CJ, Vazeou A: Prediction of albuminuria by different blood pressure measurement methods in type 1 diabetes: a pilot study. Hypertens Res 2009, 32(8):680-684.

29. Cerasola G, Mulè G, Cottone S, Nardi E, Cusimano P: Hypertension, microalbuminuria and renal dysfunction: the Renal Dysfunction in Hypertension (REDHY) study. J Nephrol 2008, 21(3):368-373.

30. Wang J, Zhang L, Wang F, Liu L, Wang H, on behalf of the China National Survey of Chronic Kidney Disease Working Group: Prevalence, awareness, treatment, and control of hypertension in china: results from a national survey. Am J Hypertens 2014, doi:10.1093/ajh/hpu053.

31. Jia W, Gao X, Pang C, Hou X, Bao Y, Liu W, Wang W, Zuo Y, Gu H, Xiang K: Prevalence and risk factors of albuminuria and chronic kidney disease in Chinese population with type 2 diabetes and impaired glucose regulation: Shanghai diabetic complications study (SHDCS). Nephrol Dial Transplant 2009, 24(12):3724-3731.

32. Lu B, Wen J, Song XY, Dong XH, Yang YH, Zhang ZY, Zhao NQ, Ye HY, Mou B, Chen FL, Liu Y, Shen Y, Wang XC, Zhou LN, Li YM, Zhu XX, Hu RM: High prevalence of albuminuria in population-based patients diagnosed with type 2 diabetes in the Shanghai downtown. Diabetes Res Clin Pract 2007, 75(2):184-192.

33. Parving HH, Lewis JB, Ravid M, Remuzzi G, Hunsicker LG, DEMAND investigators: Prevalence and risk factors for microalbuminuria in a referred cohort of type II diabetic patients: a global perspective. Kidney Int 2006, 69(11):2057-2063.

34. Wan Nazaimoon WM, Letchuman R, Noraini N, Ropilah AR, Zainal M, Ismail IS, Wan Mohamad WB, Faridah I, Singaraveloo M, Sheriff IH, Khalid BA: Systolic hypertension and duration of diabetes mellitus are important determinants of retinopathy and microalbuminuria in young diabetics. Diabetes Res Clin Pract 1999, 46(3):213-221.

35. Kawar B, Bello AK, El Nahas AM: High prevalence of microalbuminuria in the overweight and obese population: data from a UK population screening programme. Nephron Clin Pract 2009, 112(3):205-212.

36. Liu DW, Wan J, Liu ZS, Wang P, Cheng GY, Shi XZ: Association between dyslipidemia and chronic kidney disease: a cross-sectional study in the middle-aged and elderly Chinese population. Chin Med J (Engl) 2013, 126(7):1207-1212.

37. Lucove J, Vupputuri S, Heiss G, North K, Russell M: Metabolic syndrome and the development of CKD in american Indians: the strong heart study. Am J Kidney Dis 2008, 51(1):21-28.

38. Cerasola G, Cottone S, Mulè G: The progressive pathway of microalbuminuria: from early marker of renal damage to strong cardiovascular risk predictor. J Hypertens 2010, 28(12):2357-2369

39. Crews DC, Boulware LE, Gansevoort RT, Jaar BG: Albuminuria: is it time to screen the general population? Adv Chronic Kidney Dis 2011, 18(4):249-257.

40. Wiwanitkit V: Microalbumin screening. Clin Chim Acta 2010, 411(13-14):994.

41. Redon J: Measurement of microalbuminuria-what the nephrologist should know. Nephrol Dial Transplant 2006, 21(3):573-576.

42. Jafar TH, Chaturvedi $\mathrm{N}$, Hatcher J, Levey AS: Use of albumin creatinine ratio and urine albumin concentration as a screening test for albuminuria in an Indo-Asian population. Nephrol Dial Transplant 2007, 22(8):2194-2200

43. Liu K, Cooper R, McKeever J, McKeever P, Byington R, Soltero I, Stamler R, Gosch F, Stevens E, Stamler J: Assessment of the association between habitual salt intake and high blood pressure: methodological problems. Am J Epidemiol 1979, 110(2):219-226.

44. Bingham S, Cummings JH: The use of 4-aminobenzoic acid as a marker to validate the completeness of $24 \mathrm{~h}$ urine collections in man. Clin Sci (Lond) 1983, 64(6):629-635.

doi:10.1186/1471-2369-15-165

Cite this article as: Yan et al: Urinary albumin excretion and prevalence of microalbuminuria in a general Chinese population: a cross-sectional study. BMC Nephrology 2014 15:165.

\section{Submit your next manuscript to BioMed Central and take full advantage of:}

- Convenient online submission

- Thorough peer review

- No space constraints or color figure charges

- Immediate publication on acceptance

- Inclusion in PubMed, CAS, Scopus and Google Scholar

- Research which is freely available for redistribution

Submit your manuscript at www.biomedcentral.com/submit
() Biomed Central 